\title{
contenporaneity
}

Vol 9, No 1 (2021) | ISSN 2153-5914 (online) | DOI 10.5195/contemp/2021.329

http://contemporaneity.pitt.edu

\section{Colored Plexiglass: Irving and Aaronel deRoy Gruber Foundation Gallery Inaugural Exhibition}

Irving and Aaronel deRoy Gruber Foundation Gallery

Paulina Pardo Gaviria

\section{Exhibition Review}

Exhibition Schedule: Irving and Aaronel deRoy Gruber Foundation Gallery, Pittsburgh PA, January 24 - September 1, 2020.

\section{About the Author}

Paulina Pardo Gaviria is a Lecturer in the School of Art at California State University, Long Beach, and specializes in the history of modern and contemporary art of the Americas. Her scholarship focuses on the introduction of experimental artistic strategies and the artistic networks created around institutional venues of modern and contemporary art in Brazil beginning in the 1970s and at a time of military dictatorship. In 2020, Paulina received her Ph.D. from the History of Art and Architecture department at the University of Pittsburgh; her dissertation is titled "Letícia Parente: Embodying New Media Art Strategies in 1970s Brazil." Paulina is currently a Lecturer in the School of Art at California State University, Long Beach. 


\section{Colored Plexiglass: Irving and Aaronel deRoy Gruber Foundation Gallery Inaugural Exhibition}

\author{
Irving and Aaronel deRoy Gruber \\ Foundation Gallery
}

\author{
Paulina Pardo Gaviria
}

The inaugural exhibition of the Irving and Aaronel deRoy Gruber Foundation Gallery showcases kinetic artworks that Aaronel deRoy Gruber created in collaboration with and against the background of a city informed by steel mills, furnaces, and cokeprocessing plants. The exhibition at the deRoy Gruber Foundation Gallery, which opened on January 24, 2020, in Pittsburgh, PA, presents a large selection of the vibrant works that deRoy Gruber created at the peak of her artistic career, between the 1960s and 1980s. For many visitors, particularly friends and colleagues of the artist, the opening of this exhibition felt like a celebration of her prolific career. For many others, including myself, it offered a fascinating introduction to the production of a local female artist who made sophisticated use of colorful materials and translucent supports.

Organized loosely in chronological order, the exhibition of the deRoy Gruber Foundation Gallery contains nearly one hundred works currently in the foundation's and the family's collections, ranging from painting to print, sculpture to photography. This exhibition opens with a handful of abstract paintings that deRoy Gruber created in the early 1960s. These paintings give way to the central section of the exhibition, which offers an array of movable Plexiglass sculptures and silkscreen prints with geometric forms and neon colors. Toward the back of the gallery, five Plexiglass sculptures on individual pedestals are accompanied by architectural photographs that deRoy Gruber took throughout her life, and by ephemera documentation and an original maquette of deRoy Gruber's public art projects. Curated by the foundation's executive director, Brittany Reilly, the inaugural exhibition of the deRoy Gruber Foundation Gallery can be visited online through a permanent Virtual 360 Tour.

This exhibition of works by deRoy Gruber, a life-long member of the Associated Artists of Pittsburgh (AAP), was concurrent with two other exhibitions of AAP members, past and present, organized by the University of Pittsburgh Art Gallery (UAG). The exhibition of the deRoy Gruber Foundation Gallery together with Mary Ethel McAuley: Behind the German Lines and Three Artists (Three Women) at the UAG demonstrate the breadth and quality of professional practices that women artists have carried out in Pittsburgh since the early 1900s.

Born and raised in Pittsburgh, Aaronel deRoy Gruber (1918-2011) produced most, if not all, of her work in conversation with Pittsburgh's industrial developments. She graduated from Carnegie Institute of Technology (now Carnegie Mellon University) with a bachelor of science degree in 1940, five years before Andy Warhol enrolled in the same program. The year deRoy completed her professional education, she married Irving Gruber, a steel forgings executive who would become president of American Forge and Manufacturing Company, a steel company located along Pittsburgh's Allegheny River. In the early 1960s, deRoy Gruber, a prominent participant in the AAP annual exhibitions, established contact with sculptor David Smith, who, while serving as a juror for the AAP annual exhibition, visited American Forge and Manufacturing Company looking for a steel supplier for his own practice. Subsequently, deRoy Gruber and Smith cultivated a friendship based on collegiality and maintained through personal correspondence. Their friendship, and Smith's influence, is evident in deRoy Gruber's production of industrially manufactured geometrical sculptures that, since the 1960s, have been included in collective and solo exhibitions across the eastern United States and in the art collections of New York- and Appalachia-based corporations.

DeRoy Gruber heavily relied on manufacturing processes and products for her artistic creations at a time when plastic was the future and before an era of environmental awareness. 
As shown in the inaugural exhibition of the deRoy Gruber Foundation Gallery, for her sculptures, based on steel and aluminum, two pillars of Pittsburgh's centuries-old industry, deRoy Gruber bent acrylic sheets to produce airy volumes filled with vibrant colors. During the 1970s, her studio was located on the premises of Engineered Products Inc. (EPI), and her assistant was a retired steel worker. In her EPI studio and with access to industrial machinery, deRoy Gruber prepared wood-frame molds for the Plexiglass sculptures that she processed through valves, presses, vacuums, and room-size ovens with the help of her assistant and plant technicians. [Figs. 1-3]

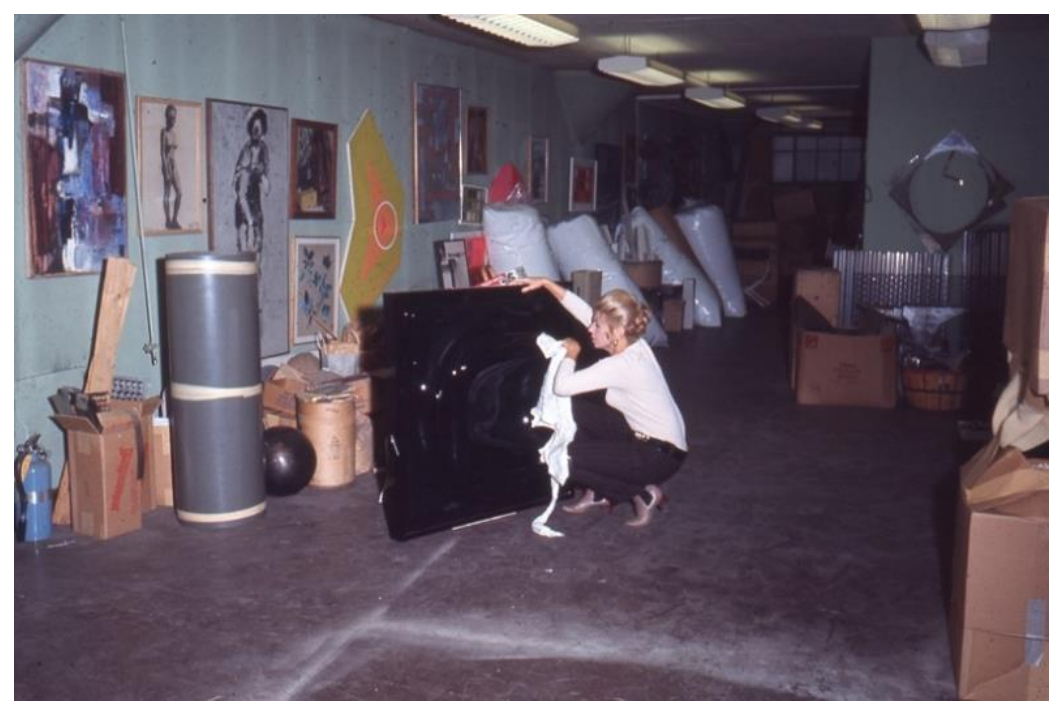

Figure 1 Photographer unknown, Artist Aaronel deRoy Gruber polishing completed vacuum-formed Plexiglas sculpture in her studio at Engineered Products Inc., Pittsburgh, PA., approximately 1970. Digitized photograph. Image courtesy of the Irving and Aaronel deRoy Gruber Foundation, Pittsburgh.

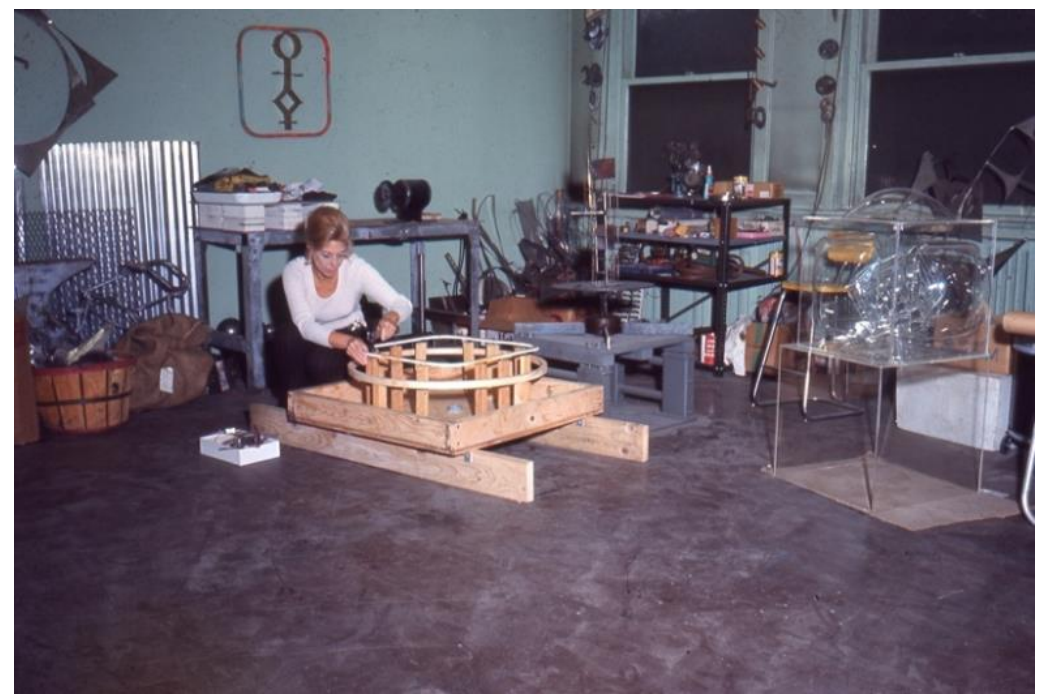

Figure 2 Photographer unknown, Artist Aaronel deRoy Gruber preparing custom wood framework and molds in her studio at Engineered Products Inc., Pittsburgh, PA., approximately 1970. Digitized photograph. Image courtesy of the Irving and Aaronel deRoy Gruber Foundation, Pittsburgh. 


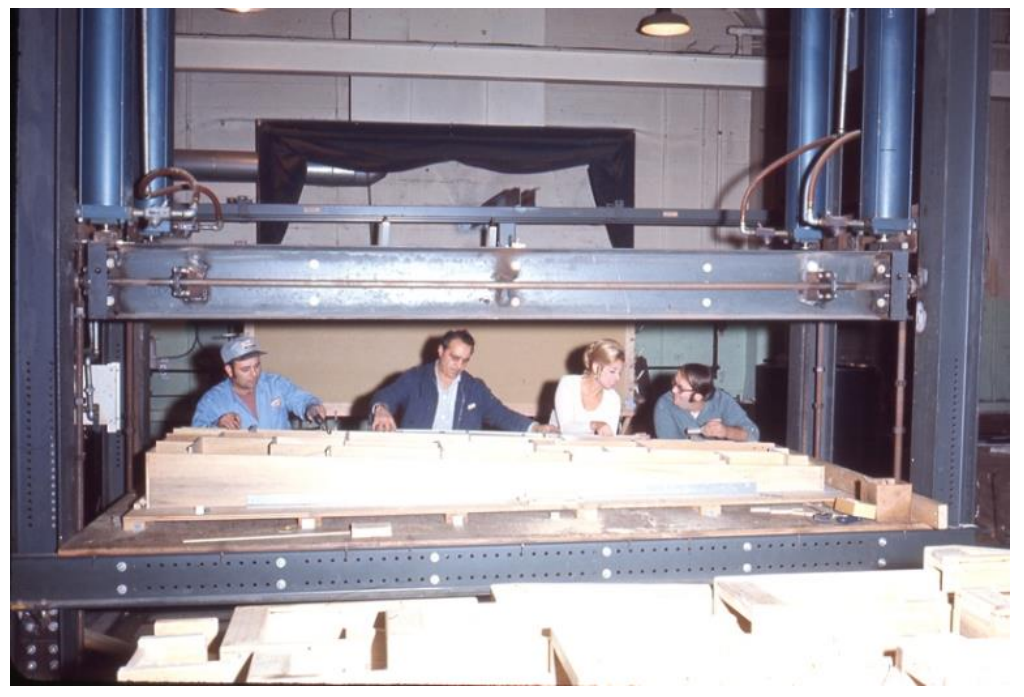

Figure 3 Photographer unknown, Artist Aaronel deRoy Gruber and technicians preparing to lower vacuum-forming and heated press at Engineered Products Inc., Pittsburgh, PA., PA., approximately 1970. Digitized photograph. Image courtesy of the Irving and Aaronel deRoy Gruber Foundation, Pittsburgh.

Made of acrylic and aluminum, Moment in Time (1968) and Life of its Own (1972) exemplify deRoy Gruber's use of industrial materials for the creation of geometric sculptures defined by clean-cut lines, solid hues of rainbow-like colors, and the incorporation of movement, either through electrical motors or optical illusions. These works, along with numerous Plexiglass sculptures that deRoy Gruber created using vacuum-forming techniques, are at the core of the inaugural exhibition of the deRoy Gruber Foundation Gallery. Mounted on an opaque black Plexiglass pedestal designed by deRoy Gruber, Moment in Time (14.5 x $14.5 \times 18.5 \mathrm{in})$ symmetrically displays the plastic possibilities of acrylic sheets. In this sculpture, six sheets are organized in a vertical composition. Two solid, clear blue outer sheets sandwich two orange and two deep green sheets at the core. All six sheets are curved at the center, with half-circle protuberances that fit into each other to create inner-circle balloons of superimposed color shades.

Similarly, Life of its Own is composed of a transparent cube that contains within it an additional smaller, grey-shaded, translucent cube. The outer cube is suspended from an aluminum arm attached to a squared chrome-plated base. Both cubes are tilted, resting on one of their corners. This $34 \times 27 \times 26$-inch sculpture is illuminated from its base, and an electrical mechanism constantly rotates both cubes on their axes. Adding to the formal complexity of this work, each side of the cubes features deRoy Gruber's signature form: a rounded square expanding the volume outward and puffing out colored Plexiglass as if filling the work with air. The half-circle and rounded square volumes formed in otherwise flat acrylic sheets are achieved with industrial vacuum techniques. Although far removed from today's ecological concerns, deRoy Gruber was highly aware of the economic and political tensions contained in the plastic material and the time-consuming nature of its production. In the artist's text "Creating a Sculpture in Plastic," written in the early 1970s and currently filed in the foundation archives, deRoy Gruber states, "At present due to the oil shortages the monomers used in making plastics are in short supply. This has resulted in less available plastic, increased cost of material, and production of a limited number of transparent colors." The combination of industrial processes of shaping and dying plastic, a central feature in deRoy Gruber's colorful works, can be especially appreciated in Life of its Own, displayed near the entrance of the exhibition and using the original motor, wiring, and lightbulbs. 
Throughout the deRoy Gruber exhibition, several other sculptures echo these vibrant acrylic bubbles, reproducing them in different scales and colors; among the smallest is a $3 \mathrm{x}$ 3 -inch, orange and pink sculpture filled with liquid and hanging from a chain. Identified as Pendant Necklace this plastic work of jewelry gestures toward the jewelry store that the deRoy family operated in Pittsburgh for several generations and conjures the wearable, small-scale mobiles of Alexander Calder. DeRoy Gruber's artistic production can further be compared--in her use of neon colors, industrial materials, and electric motors--to the work of both Parisbased Venezuelan artist Carlos Cruz-Diez and Colombian radical artist Feliza Bursztyn. Closer to Pittsburgh, between the 1960s and 1980s, deRoy Gruber was conversant, for instance, with the Plexiglass sculptures of Heinz Mack, Les Levine, DeWain Valentine, and Craig Kauffman (the last two associated with the Light and Space Movement), with whom she participated in the 1968 exhibition Made of Plastic at the Flint Institute of Arts and the 1969 Plastic in Editions at the Jewish Museum in New York. Created amid Pittsburgh's mills and currently displayed in the exhibition of the deRoy Gruber Foundation Gallery, deRoy Gruber's artistic production is a fantastic testimony to the industrial processes developed in US urban centers and the individual creations of one of the few recognized female artists that brought colorful light to these smoky cities.

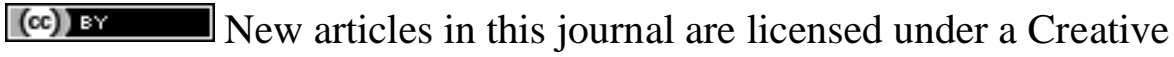

\section{Commons Attribution 4.0 United States License.}

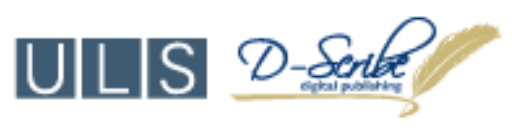

This journal is operated by the University Library System of the University of Pittsburgh as part of its D-Scribe Digital Publishing Program, and is co-sponsored by the University of Pittsburgh Press. 